\title{
Gonadotropin-releasing hormone inhibits the proliferation and motility of nasopharyngeal carcinoma cells
}

\author{
LOONG HUNG TENG ${ }^{1}$, MUNIRAH AHMAD ${ }^{1}$, WAYNE TIONG WENG NG ${ }^{1}$, SUBATHRA SABARATNAM ${ }^{2}$, \\ MARIA ITHAYA RASAN ${ }^{3}$, ISHWAR PARHAR $^{4}$ and ALAN SOO BENG KHOO ${ }^{1}$ \\ ${ }^{1}$ Molecular Pathology Unit, Cancer Research Centre, Institute for Medical Research, Kuala Lumpur 50588; \\ ${ }^{2}$ Department of Pathology, Sultanah Aminah Hospital, Jeffrey Cheah's School of Medicine and Health Sciences, \\ Monash University, Johor Bahru, Johor 80100; ${ }^{3}$ Department of Otorhinolaryngology, Hospital Tengku Ampuan Rahimah, \\ Klang, Selangor 41200; ${ }^{4}$ Brain Research Institute, School of Medicine and Health Sciences, \\ Monash University Sunway Campus, Petaling Jaya, Selangor 47500, Malaysia
}

Received September 18, 2014; Accepted June 5, 2015

DOI: $10.3892 / \mathrm{mmr} .2015 .4043$

\begin{abstract}
Gonadotropin-releasing hormone (GnRH), or its analogues have been demonstrated to exhibit anti-proliferative effects on tumour cells in ovarian, endometrial and breast cancer through GnRH-receptors (GnRH-R). However, the role of GnRH in nasopharyngeal carcinoma (NPC) remains to be elucidated. In order to investigate the effects of $\mathrm{GnRH}$ in NPC, the present study examined the expression of the GnRH-R transcript in NPC and investigated the phenotypic changes in HK1 cells, a recurrent NPC-derived cell line, upon receiving GnRH treatment. Firstly, the GnRH-R transcript was demonstrated in the NPC cell lines and four snap frozen biopsies using reverse transcription-quantitative polymerase chain reaction. In addition, immunohistochemistry revealed the expression of GnRH-R in two of the eight (25\%) NPC specimens. Treatment with GnRH induced a rapid increase in intracellular ionised calcium concentration in the NPC cells. GnRH and its agonists, triptorelin and leuprolide, exerted anti-proliferative effects on the NPC cells, as determined using an MTS assay. GnRH did not induce any cell cycle arrest in the HK1 cells under the conditions assessed in the present study. Time-lapse imaging demonstrated a reduction in cell motility in the GnRH-treated cells. In conclusion, GnRH, or its analogues may have antitumour effects on NPC cells. The consequences of alterations in the levels of GnRH on the progression of NPC require further examination.
\end{abstract}

Correspondence to: Dr Alan Soo Beng Khoo, Molecular Pathology Unit, Cancer Research Centre, Institute for Medical Research, Jalan Pahang, Kuala Lumpur 50588, Malaysia

E-mail: alankhoo@imr.gov.my

Key words: gonadotropin-releasing hormone, nasopharyngeal carcinoma, HK1 cells, cell line

\section{Introduction}

Gonadotropin-releasing hormone $(\mathrm{GnRH})$ is a hypothalamic hormone, which regulates reproduction. Pulsatile secretion of GnRH stimulates the secretion of follicular stimulating hormone (FSH) and luteinizing hormone (LH) from the pituitary gland. These pituitary hormones stimulate the synthesis of gonadal steroid hormones and gametogenesis in the gonads (1). It has been established that continuous stimulation by $\mathrm{GnRH}$ agonists downregulates $\mathrm{GnRH}$ receptors ( $\mathrm{GnRH}-\mathrm{R})$ in the pituitary, resulting in a decrease in the secretions of FSH and LH, ultimately resulting in chemical castration (2).

GnRH binds to GnRH-R, resulting in effects on cellular function (3). Upon binding to its ligand, GnRH-R activates various intracellular mechanisms mediated by $\mathrm{G}$-protein coupled receptor (GPCR) signalling, which leads to the inhibition of mitogenic signalling and results in a reduction in cell proliferation and arrest of the cell cycle in the G0/G1 phase (1).

The presence of GnRH receptors in gonadal steroid-dependent organs and tissues, including breast, ovary, endometrium and prostate tissue, and in cancer in the respective organs has been reported. The expression of GnRH-R has been observed in $80 \%$ of human ovarian and endometrial cancer cases and $50 \%$ of breast cancer cases (4). In addition, GnRH and/or its agonists have been demonstrated to have direct inhibitory effects on cell proliferation or invasiveness in breast (5), prostate (6), endometrial (7) and ovarian (8) cancer.

The effects of GnRH on cancer in peripheral organs other than the gonadal steroid-dependent organs remain to be fully elucidated. GnRH-R has been reported to be expressed in colorectal carcinoma cells and GnRH analogues exert direct inhibitory effects on the cells (9). GnRH has been reported to suppress the motility and invasiveness of melanoma cells (10). By contrast, while GnRH and GnRH-R are expressed in bladder cancer, treatment with GnRH does not have any effects on the proliferation of the cells (11).

GnRH analogues, including leuprolide and triptorelin, which have been developed to treat gonadal steroid-dependent cancer through suppression of the pituitary gonadal axis, have also been observed to have direct effects on 
GnRH-R-expressing cancer cells (12). In addition, the presence of GnRH receptors in cancer cells has been suggested for use in molecular targeted therapies. Anticancer drug treatments have been conjugated to $\mathrm{GnRH}$ analogues to target cancer cells expressing GnRH-R (5). For example, cytotoxic-radical-conjugated GnRH analogues have been observed to have anticancer effects in colorectal carcinoma (9).

Nasopharyngeal carcinoma (NPC) is a major type of cancer in southern China, North Africa and Southeast Asian countries, including Malaysia (13). Patients with NPC often present in the late stages of the disease at the time of diagnosis (14). Radiotherapy is the primary modality of treatment for this type of cancer, however this type of therapy risks damage to the hypothalamic-pituitary axis due to the location of the nasopharynx (15). If GnRH has effects on NPC cells, alteration of secretion of GnRH may affect the progression of NPC. To investigate this, the present study aimed to examine the expression of GnRH-R in NPC tumours, and the effects of GnRH on the NPC cells. To address this, the present study examined the expression of GnRH-R in NPC tumors, and investigated the effects of GnRH on the viability, motility and signaling of NPC cells

\section{Materials and methods}

GnRH and its analogues. Human GnRH and the GnRH analogues, leuprolide and triptorelin, were purchased from Sigma-Aldrich (St. Louis, MO, USA).

Snap-frozen biopsies, cell lines and culture conditions. Snap-frozen biopsies were obtained from the Department of Otorhinolaryngology, Hospital Tengku Ampuan Rahimah (Klang, Malaysia). Written informed consent was obtained from all patients prior to the biopsy procedures. The tissues were immediately snap-frozen and preserved in liquid nitrogen prior to RNA extraction. The diagnosis of NPC was confirmed from the hospital histopathology reports. All procedures for obtaining and investigating human tissues were approved by the Medical Research and Ethics Committee (Ministry of Health, Malaysia). The HK1 cells, which were provided by Professor GSW Tsao, (Hong Kong University, Hong Kong, China), is an Epstein-Barr virus (EBV)-negative NPC cell line, previously derived from a patient with recurrent NPC from Hong Kong (16) was used in the present study. The HK1 cells were maintained at $37^{\circ} \mathrm{C}$ in a humidified atmosphere of $5 \% \mathrm{CO}_{2}$ in RPMI 1640 medium (Gibco Life Technologies, Carlsbad, CA, USA), supplemented with $10 \%$ fetal bovine serum (FBS; Gibco Life technologies), $50 \mathrm{U} / \mathrm{ml}$ penicillin (Invitrogen Life Technologies, Carlsbad, CA, USA) and $50 \mu \mathrm{g} / \mathrm{ml}$ streptomycin (Invitrogen Life Technologies). The identity of the HK1 cells was validated by DNA fingerprinting using the AmpFiSTR Identifiler $^{\circledR}$ PCR amplification kit (Applied Biosystems Life Technologies, Foster City, CA, USA) and confirmed mycoplasma free by regular assessment using a VenorGeM ${ }^{\circledR}$ mycoplasma detection kit (Minerva Biolabs GmbH, Berlin, Germany). The C-666-1 cells, provided by Dr KW Lo (The Chinese University of Hong Kong, Hong Kong, China) is an EBV-positive NPC cell line (17), were maintained in the same conditions as the HK1 cells, but with 15\% FBS. NP69 (18) and NP460hTERT (19) are immortalised nasopharyngeal epithelial cell lines. The NP69 cells were maintained in keratinocyte-serum free medium (KSFM) supplemented with $25 \mu \mathrm{g} / \mathrm{ml}$ bovine pituitary extract and $0.16 \mathrm{ng} / \mathrm{ml}$ recombinant epidermal growth factor (Gibco Life Technologies). The NP460 cells were maintained in a 1:1 ratio of defined KSFM supplemented with growth factor (Gibco Life Technologies) and EpiLife medium supplemented with EpiLife Defined Growth Supplement (Cascade Biologics, Portland, OR, USA). HK1 cells were used throughout the present study, whereas the C-666-1, NP69 and NP460hTERT cells were only used in the reverse transcription-quantitative polymerase chain reaction (RT-qPCR) experiments.

Gene expression omnibus (GEO) database data mining. A microarray dataset for NPC (GSE12452) was retrieved from the GEO database (http://www.ncbi.nlm.nih. gov/sites/GDSbrowser). The raw data were re-analysed using GeneChip ${ }^{\circledR}$ Operating Software version 5.0 (Affymetrix, Inc., Santa Clara, CA, USA) and the number of specimens expressing the GnRH and GnRH-R transcripts were determined.

$R T-q P C R$ of $G n R H-R m R N A$. Total RNA was isolated from the homogenised snap-frozen nasopharyngeal cancer tissue specimens and cultured nasopharyngeal cancer cells using an RNeasy mini kit (Qiagen GmbH, Hilden, Germany), according to the manufacturer's instructions. First strand complementary DNA (cDNA) was synthesised from $1 \mu \mathrm{g}$ total RNA using a High-Capacity cDNA Reverse Transcription kit (Applied Biosystems Life Technologies). The primer sequences for Type-1 GnRH-R were as follows: Sense 5'-TCTGGAAAG ATCCGAGTGAC-3' and antisense 5'-TCAGCCATCAAC AACAGCATCCC-3'; and the primer sequences for Type 1 GnRH (GnRH-I) were as follows: Sense 5'-TTTCCAAGA GATAGTCAAAGAGGTT-3' and antisense 5'-TCAGACTTT CCAGAGCTCCTTTCAG-3'. RT-qPCR was performed on a Thermal cycler (C1000 Thermal Cycler, Bio-Rad Laboratories, Inc., Hercules, CA, USA) using the cDNA product (1:25) as a template, $0.2 \mu \mathrm{M}$ of each primer and $1 \mathrm{X}$ i-PCR master mix (i-DNA Biotechnology Pte. Ltd., Singapore). The cycling conditions were as follows: Initial denaturation step at $94^{\circ} \mathrm{C}$ for $5 \mathrm{~min}$, denaturation step at $94^{\circ} \mathrm{C}$ for $30 \mathrm{sec}$, annealing step at $58^{\circ} \mathrm{C}$ for $30 \mathrm{sec}$ and an extension step at $72^{\circ} \mathrm{C}$ for $30 \mathrm{sec}$, and a final extension for $10 \mathrm{~min}$ at $72^{\circ} \mathrm{C}$ following the final cycle. The reactions were subjected to 35 cycles in total. As an internal reference, $\beta$-actin mRNA was amplified from the same samples. The identity of the representative amplified qPCR products were confirmed by sequencing (First Base Laboratories, Seri Kembangan, Malaysia).

Immunohistochemistry. The protein expression of GnRH-R in the NPC tissues was investigated using immunostaining with mouse anti-human GnRH-R monoclonal antibody (Clone A9E4; Leica Biosystems, Newcastle Upon Tyne, UK). Sections $(4 \mu \mathrm{M})$ from the formalin-fixed, paraffin-embedded archival tissues were cut using a microtome (HM340E; Thermo Fisher Scientific, Walldorf, Germany). These sections were then dewaxed, and antigen retrieval was performed using citrate buffer (Dako Target Retrieval Solution, Glostrup, Denmark). The endogenous peroxidase activity was inhibited 
using 3.3\% hydrogen peroxide. The tissue sections were rinsed with 1X Tris-buffered saline (TBS) buffer (Dako Wash Buffer; Dako Life Technologies)and incubated with anti-GnRH-R antibody (1:50 dilution) at room temperature for $2 \mathrm{~h}$. Following rinsing with $1 \mathrm{X}$ TBS, the sections were incubated for $30 \mathrm{~min}$ at room temperature with anti-rabbit/mouse secondary antibody (1:5; K5007; Dako Life Technologies). The antigen-antibody complex was detected using avidin-biotin peroxidase complex solution containing 3,3'-diaminobenzidine stain and counterstained with hematoxylin (Dako Life Technologies, Glostrup, Denmark). Negative controls were performed by omitting the primary antibody. Tissue sections of breast cancer were used as a positive control.

Assessment of proliferative activity, determined using a 3-(4,5-dimethylthiazol-2-yl)-5-(3-carboxymethoxyphenyl)-2(4-sulfophenyl)-2H-tetrazolium (MTS) colorimetric assay. An MTS assay was performed using a CellTiter $96^{\circledR}$ AQueous Non-Radioactive Cell Proliferation assay kit (Promega Corporation, Madison, WI, USA). The HK1 cells were rendered quiescent by incubation under serum-free conditions for $16 \mathrm{~h}$ at $37^{\circ} \mathrm{C}$, following which the cells were cultured at an approximate density of $4.0 \times 10^{3}$ cells/well in 96-well flat-bottom cell culture plates (Orange Scientific, Braine-l'Alleud, Belgium) containing 10\% FBS supplemented medium with and without graded concentrations of GnRH or its analogues $\left(10^{-12}-10^{-9} \mathrm{M}\right)$ for $1-6$ days at $37^{\circ} \mathrm{C}$. The culture medium and $\mathrm{GnRH}$ or analogues were refreshed each day.

The viability of the cells were determined each day of treatment with GnRH using the MTS assay. Each day, $20 \mu 1 \mathrm{MTS}$ solution was added to each well and the plates were incubated at $37^{\circ} \mathrm{C}$ for $4 \mathrm{~h}$. The absorbance was measured on an MRX 96-well plate reader (Dynatec Laboratories, Houston, TX, USA) at a wavelength of $490 \mathrm{~nm}$ and a reference wavelength of $630 \mathrm{~nm}$. Statistical calculations were performed using SPSS Advanced Statistical Software SPSS Inc, Chicago, IL, USA). Student's t-test was used to determine the significance of the comparison. $\mathrm{P}<0.05$ was considered to indicate a statistically significant difference.

Calcium imaging. The HK1 cells were seeded at a density of $2.5 \times 10^{5}$ cells/plate in poly-L-lysine (Sigma-Aldrich)-coated $30 \mathrm{~mm}$ WillCo-dish ${ }^{\circledR}$ glass bottom dishes (WillCo Wells, Amsterdam, The Netherlands) in the presence of $10 \%$ FBS RPMI and cultured overnight at $37^{\circ} \mathrm{C}$. The cells were then stained with $5 \mu \mathrm{M}$ Fluo3-Am (Molecular Probes Life Technologies, Carlsbad, CA, USA) and $0.1 \%$ pluronic acid (Sigma-Aldrich) in Hank's balanced salt solution-bovine serum albumin-probenecid (HBSS-BSA-probenecid; AfCS Solution Protocol ID PS00000574; pH 7.45; Gibco Life Technologies) and incubated in the dark for $30 \mathrm{~min}$ at $37^{\circ} \mathrm{C}$. The cells were washed in HBSS-BSA-probenecid (Sigma-Aldrich) at least twice, and incubated in fresh RPMI with $10 \%$ FBS. The cells were subjected to time-lapse live cell imaging. The images were captured under a Nikon Eclipse Ti-E automated inverted fluorescence microscope (Nikon, Tokyo, Japan; magnification, x20) at a speed of four frames/sec for 2 min and, 2 sec after the start of image capture, the cells were treated with ionomycin $\left(10^{-5} \mathrm{M}\right.$, positive control; Calbiochem, Darmstadt, Germany), water (control) or $\mathrm{GnRH}\left(10^{-10} \mathrm{M}\right)$, respectively.
The intracellular intensity changes of 10 cells from each sample were measured and compared using NIS Elements software version 4.0 (Nikon). Student's t-test was performed using SPSS. $\mathrm{P}<0.05$ was considered to indicate a statistically significant difference.

Cell-cycle analysis. The HK1 cells were seeded into 100-mm culture plates at a density of $4.0 \times 10^{5}$ cells/dish in $6 \mathrm{ml}$ culture medium. The cells were treated with $\mathrm{GnRH}$ at a concentration of $10^{-9} \mathrm{M}$ for $48 \mathrm{~h}$. Untreated cells were used as a control. The cells were prepared for cell-cycle analysis using a CycleTEST PLUS DNA Reagent kit (BD BioSciences, San Jose, CA, USA). A pellet containing $5 \times 10^{5}$ cells was gently resuspended in $250 \mu \mathrm{l}$ solution $\mathrm{A}$, containing trypsin (BD Biosciences), followed by $200 \mu \mathrm{l}$ solution B, containing trypsin inhibitor and RNase A (BD Biosciences), and incubated at room temperature for $10 \mathrm{~min}$ each. A total of $200 \mu \mathrm{l}$ propidium iodide (PI) was added and the cell suspensions were incubated at $4^{\circ} \mathrm{C}$ in the dark for $10 \mathrm{~min}$. Flow-cytometric analysis of the cellular DNA content was performed using Cell Quest Pro software version 6.0 (BD Biosciences) on a FACS Calibur flow cytometer (BD BioSciences) and the results were analysed using ModFit $L T^{\mathrm{TM}}$ software version 4.0 (Verity Software House, Inc., Topsham, ME, USA).

Time-lapse microscopy. The HK1 cells were starved overnight with $0.5 \%$ BSA (Sigma-Aldrich, MO, USA) in RPMI medium. A total of $1.5 \times 10^{5}$ cells were then seeded in glass-bottom culture plates with $1 \%$ FBS in RPMI medium. Following attachment, the cells were treated with $10^{-10} \mathrm{M} \mathrm{GnRH}$, while untreated cells served as a control. Cell migration and changes in morphology were examined under a Nikon Eclipse Ti-E inverted microscope (Nikon) with a 10x differential interference contrast objective lens for $16 \mathrm{~h}$, with a time-lapse frame interval of $10 \mathrm{~min}$. During image capture, the cells were cultured in $5 \% \mathrm{CO}_{2}$ at $37^{\circ} \mathrm{C}$ within a humidified stage chamber. Image-Pro Plus version 6.3 (Media Cybernetics, Inc., Rockville, MD, USA) was used for analysis. The maximum speed of all cells within the frames were measured after $10 \mathrm{~h}$ treatment, and the mean maximum speed of the samples were compared using Student's t-test on GraphPad Prism 5 (GraphPad Software, Inc., La Jolla, CA, USA).

\section{Results}

GnRH-R is expressed in NPC. The microarray dataset deposited by Sengupta et al (20) on the public database, GEO, revealed that GnRH-R was expressed in 22 of the 31 NPC specimens (71\%), while the hormone, GnRH, was expressed in 25 of the 31 specimens $(81 \%)$. To verify this finding, several snap-frozen NPC biopsies were examined for their mRNA expression levels of GnRH-R and GnRH. As shown in Fig. 1A, amplified products of GnRH-R and GnRH, with predicted sizes of $209 \mathrm{bp}$ and $116 \mathrm{bp}$, respectively, were observed from at least four samples, with a faint $\beta$-actin (internal control) band observed in sample 3 . The PCR products were confirmed by sequencing.

The GnRH-R and GnRH transcripts were expressed in the NPC and nasopharyngeal epithelial cell lines (Fig. 1B). In addition, GnRH-R was detected by immunohistochemically in at least $25 \%(2 / 8)$ of NPC specimens (Fig. 1C). The 

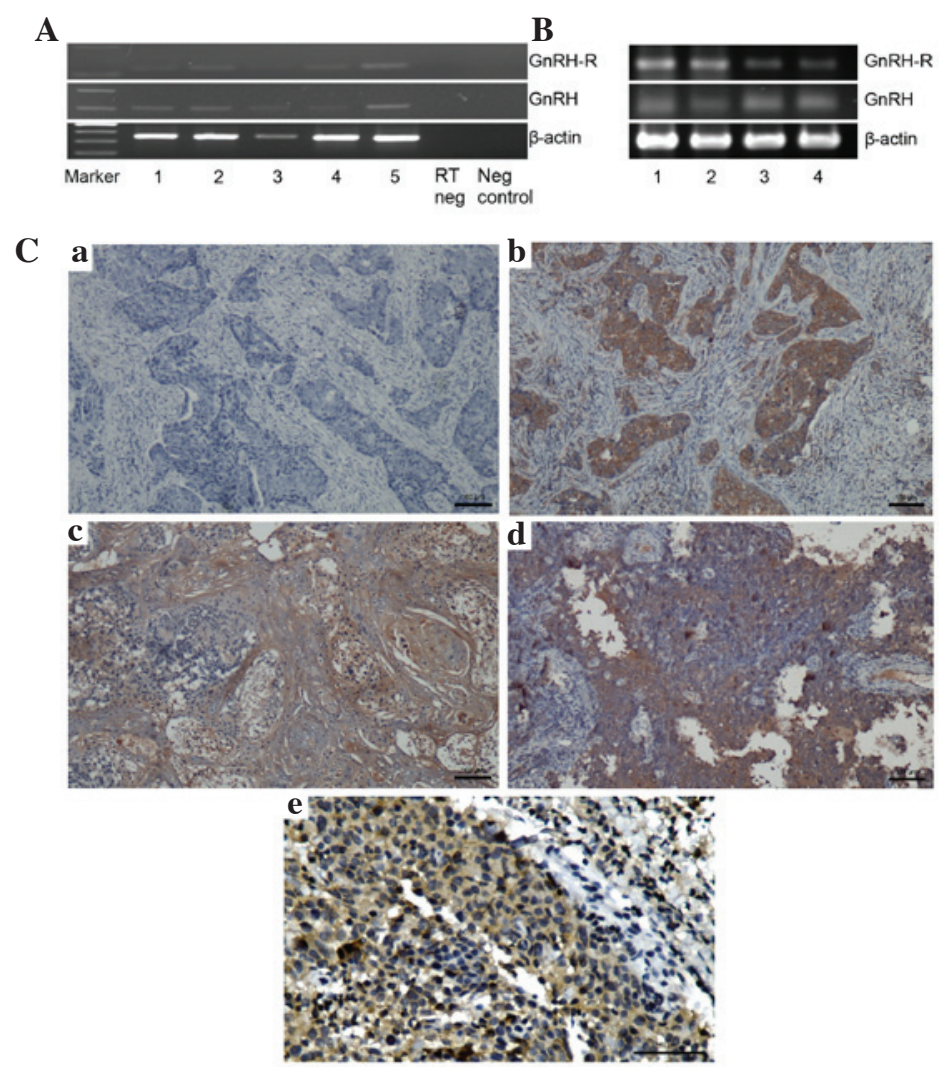

Figure 1. Expression levels of GnRH-R and GnRH in NPC. (A) mRNA expression levels of GnRH-R and GnRH in biopsies from patients with NPC, determined using reverse transcription-quantitative polymerase chain reaction. The GnRH-R and GnRH transcripts were detected in the majority of specimens (Lane 1, 2, 4 and 5). $\beta$-actin mRNA was amplified as a control. (B) mRNA expression levels of GnRH-R and GnRH in the NPC cell lines (lane 1, HK1; lane 2, C666-1) and nasopharyngeal epithelial cells (lanes 3 and 4, NP69 and NP460). (C) Immunohistochemistry for the expression of GnRH-R in NPC xenografts and specimens, visualized using a Nikon ECLIPSE Ti microscope (Nikon Corporation, Tokyo, Japan). Breast cancer tissue was stained as a positive control (b), while the primary antibody was omitted as a negative control (a). GnRH-R was detected in HK1 NPC xenograft (c) and NPC biopsy (d) and (e) at a high magnification. NPC, nasopharyngeal carcinoma; GnRH, gonadotropin releasing hormone; GnRH-R, GnRH-receptor.

HK1 cells used were confirmed via DNA fingerprinting (data not shown) to be comparable to the cells used in other investigations (21).

GnRH induces an increase in ionised calcium concentration in NPC cells. Following the addition of GnRH, the fluorescence intensity of the HK1 cells increased rapidly (Fig. 2A). The fluorescence intensities of the untreated cells and vehicle control-treated cells (Fig. 2B) were determined for comparison. The cells, which were treated with GnRH exhibited a significantly higher increase in fluorescence intensity, compared with the cells in the vehicle control group $(\mathrm{P}<0.05$; Fig. 2C and D). These data suggested that transient elevation of ionized calcium concentration occurred when the HK1 cells were treated with GnRH, thus suggesting that the hormone induced calcium signalling in the NPC cells.

GnRH causes a reduction in cell viability, but does not cause cell cycle arrest. An MTS assay was used to investigate the effect of GnRH on the viability of the NPC/HK1 cells. The cells were cultured and treated with $\mathrm{GnRH}$, leuprolide or triptorelin at graded concentrations $\left(10^{-12}-10^{-9} \mathrm{M}\right)$ and assessed with MTS for up to 6 days. GnRH, at nanomolar concentrations $\left(10^{-9}-10^{-12} \mathrm{M}\right)$ significantly inhibited the growth of the cultured cells following 2, 4 and 6 days of treatment (Fig. 3A and $\mathrm{B})$. The maximum growth inhibition was reached with
$10^{-9} \mathrm{M}$ and $10^{-10} \mathrm{M}$ GnRH. Similar results were obtained with GnRH analogues (Fig. 3C and D).

DNA contents of GnRH treated or control HK1 cells were quantitated for cell cycle analysis. The distribution of cells in the different phases of the cell cycle did not significantly change following GnRH exposure (Fig. 4), suggesting that GnRH did not cause cell cycle arrest under the conditions described.

Effects of GnRH on cell morphology and migration. The HK1 cells were treated with $10^{-10} \mathrm{M} \mathrm{GnRH}$ in low serum medium prior to time-lapse-live cell microscopic imaging. The morphology and migration of the HK1 cells were observed for $16 \mathrm{~h}$ with an interval of $10 \mathrm{~min}$. The control (untreated) cells were found to proliferate, while the treated cells were found to undergo apoptosis (Fig. 5A). In general, cell motility was decreased by GnRH, which was four times slower (Fig. 5B), compared with the untreated cells.

\section{Discussion}

The expression of GnRH-R in tumour cells, including breast cancer cells, has been reported to determine the sensitivity of the cells to GnRH $(22,23)$. In the present study, the expression of GnRH-R was observed in NPC at the transcriptional level, determined in frozen biopsy samples and cell lines, and 
A

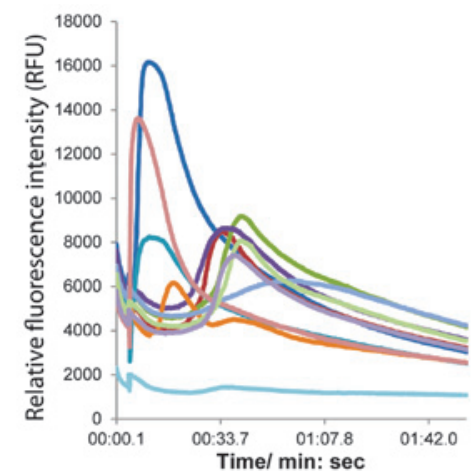

C

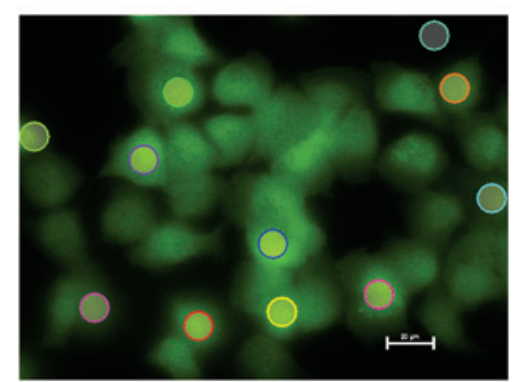

B

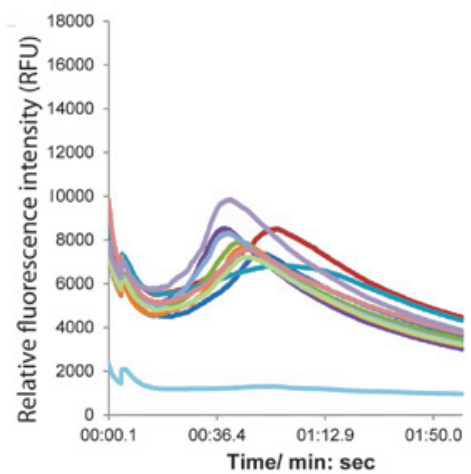

D

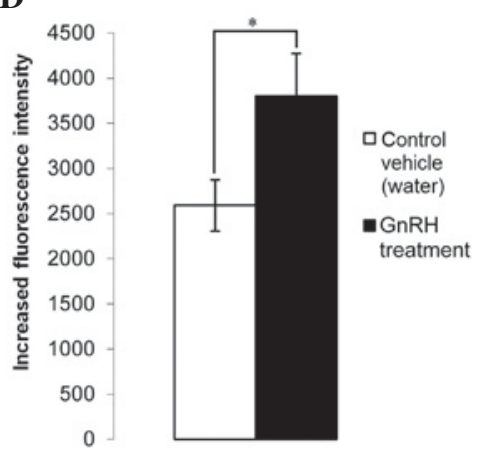

Figure 2. GnRH induces a rapid increase in intracellular ionised calcium concentration in NPC cells. Live cell calcium imaging revealed a rapid increase in ionized calcium concentration following treatment of the HK1 cells with GnRH. The fluorescence intensities of cells treated with (A) GnRH and (B) vehicle control (water) were measured. (C) A total of 10 cells and one non-cell background (circled) were selected for measurement of the fluorescence intensities. The average increase in fluorescence intensity (D) was significantly higher in cells treated with GnRH than in the cells treated with the vehicle control (P<0.05). Data are expressed as the mean \pm standard deviation. Flat lines in A and B represent the intensity changes for the non-cell areas. NPC, nasopharyngeal carcinoma; GnRH, gonadotropin releasing hormone.
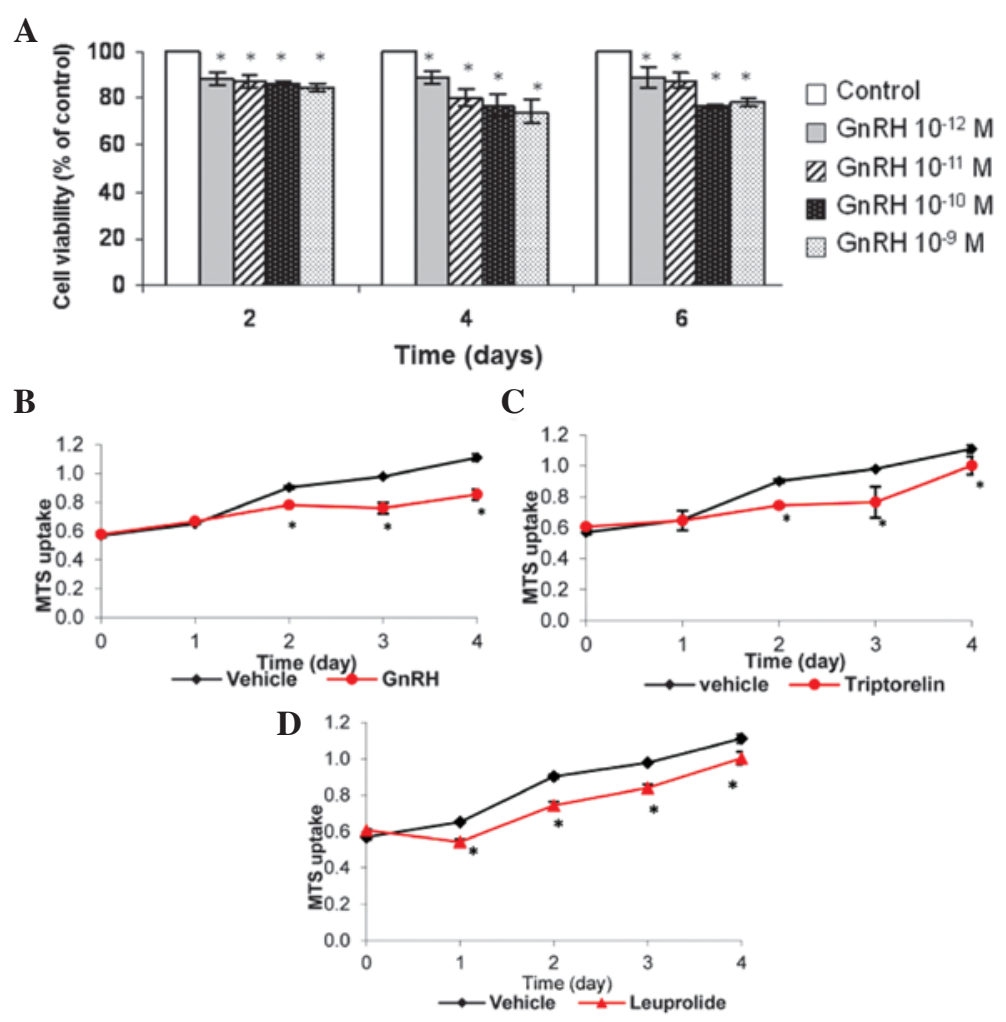

Figure 3. Effects of GnRH and GnRH agonists on the proliferation of NPC/HK1 cells, determined using a an MTS assay. The cells were cultured and treated with (A) $10^{-10} \mathrm{M} \mathrm{GnRH},(\mathrm{B}), 10^{-10} \mathrm{M}$ triptorelin or (C) $10^{-10} \mathrm{M}$ leuprolide (D). (A) Treatment with GnRH significantly decreased the proliferation of HK1 cells. (B) HK1 cell proliferation was significantly inhibited after $48 \mathrm{~h}$ of treatment with $\mathrm{GnRH}$ at $10^{-10} \mathrm{M}$. (C and D) Triptorelin and leuprolide GnRH agonists exhibited significant anti-proliferative effects on the HK1 cells. The experiments were performed in triplicate. At least three independent experiments revealed similar results, with representative results presented. " $\mathrm{P}<0.05$, compared with the- control. Data are expressed as the mean \pm standard deviation. NPC, nasopharyngeal carcinoma; GnRH, gonadotropin releasing hormone; MTS,3-(4,5-dimethylthiazol-2-yl)-5-(3-carboxymethoxyphenyl)-2-(4-sulfophenyl)-2H-tetrazolium. 

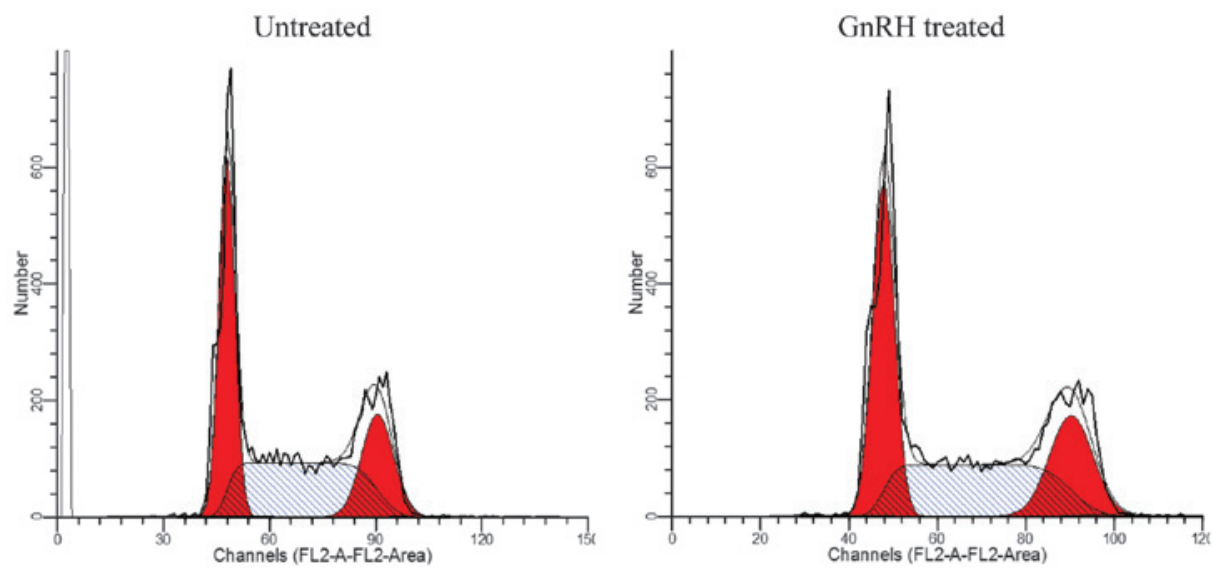

\begin{tabular}{cccc}
\hline Samples & $\mathrm{G} 0+\mathrm{G} 1$ phases & S phase & G2/M phase \\
\hline Untreated & $39.6 \pm 2.5$ & $38.3 \pm 3.8$ & $22.1 \pm 3.4$ \\
GnRH treated & $38.8 \pm 0.9$ & $37.9 \pm 3.1$ & $23.3 \pm 3.0$ \\
\hline
\end{tabular}

Figure 4. Cell cycle analysis of HK1 cells treated with GnRH. DNA content was measured using flow cytometry following treatment of the cells with GnRH for $48 \mathrm{~h}$. No significant difference was observed $(\mathrm{P}>0.05)$ in the cell cycle phases between the untreated and GnRH-treated cells under the conditions assessed. Experiments were repeated three times, with representative data presented. GnRH, gonadotropin releasing hormone.

A
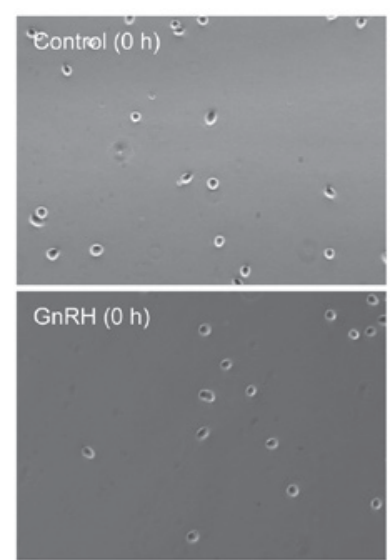
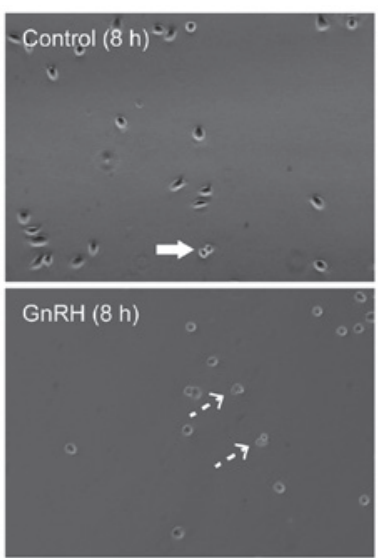
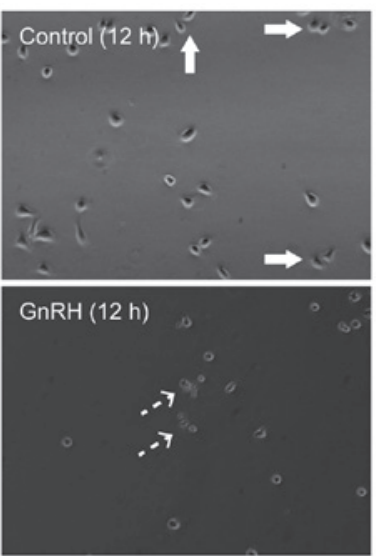

\section{$\rightarrow$ Cell blebbing}

B

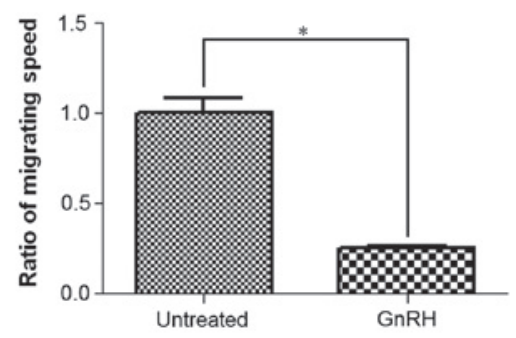

Figure 5. GnRH reduces the motility of HK1 cells. (A) Images of the cells were captured under a time-lapse microscope at $10 \mathrm{~min}$ intervals for $16 \mathrm{~h}$ following treatment with GnRH. The GnRH-treated cells exhibited reduced motility, compared with the control. Blebbing and rupture of cell membranes were observed following $8 \mathrm{~h}$ of GnRH treatment. (B) Maximum speed of each cell was measured and the mean was compared between GnRH-treated and control cells. GnRH reduced cell motility ( $\mathrm{P}<0.05)$. Experiments were repeated three times, with representative data presented as the mean \pm standard deviation. GnRH, gonadotropin releasing hormone.

protein level, determined in paraffin sections of xenograft and NPC biopsies (Fig. 1), which indicated that NPC cells potentially respond to GnRH. The data (Fig. 1B) suggested that the expression of GnRH-R was higher in the NPC cells, compared with their non-NPC counterpart, although further investigations are required to confirm this. The exploitation of GnRH-R to target cancer may be possible if the levels of GnRH-R are higher in the cancer cells than in normal cells. The protein 
expression of GnRH-R in NPC is variable. However, the detection of GnRH-R protein in a fraction (25\%) of NPC specimens suggested the potential sensitivity of a subset of NPC tumours to GnRH.

The induction of calcium signalling in NPC cells by GnRH suggest that GnRH-Rs are functional. Treatment of the NPC cells with GnRH resulted in modest anti-proliferative effects on the cells. In addition, treatment with $\mathrm{GnRH}$ resulted in the appearance of cells undergoing apoptosis as well as a reduction in motility, although modest in certain cases.

The effects of GnRH appeared to be variable. Experiments involving the treatment of cells with GnRH are complicated by several factors, including errors in measurement, which can be significant due to the low concentration of the hormone required for treatment. In addition $\mathrm{GnRH}$ activity may be affected by the stability of the hormone in solution. Goodwin et al (24) reported that the half life of GnRH in treatment of Caco-2 cells was 12.2 mins, but it is known that treatment of certain tissues with GnRH can lead to rapid desensitization of the cells to the hormone (25), leading to a reduction in the effect of GnRH. GnRH has been reported to induce opposite effects on different cell lines of similar tissue origin, including ovarian and prostate cancer (26-28). Furthermore, GnRH is reported to have biphasic effects in the cell motility and invasiveness of ovarian cancer cells (29). In addition, the GnRH-R signalling pathway may be affected by cross talk with other pathways and these pathways may vary with different cells types (30). It is also possible that differences in culture conditions can affect the activation state of these other pathways, which affect the sensitivity of the cells towards GnRH.

The GnRH-R is a GPCR, which can trigger activation of the GPCR signalling pathway, leading to cellular responses (31). During signal transduction, calcium uptake was elevated in the present study. This transient increase in ionized calcium concentration in the NPC cells upon GnRH treatment suggested the possibility that $\mathrm{GnRH}$ exerted effects on the cells through GPCR signalling.

In addition, endogenous GnRH may also affect responsiveness to a treatment. Endogenous GnRH has been revealed to promote cell proliferation in ovarian cancer (32). The levels of endogenous GnRH in the cells may be controlled by a regulatory feedback mechanism, which in turn could be affected by the presence of exogenous GnRH. Therefore, treatment with exogenous GnRH may not only directly affect the cells, but it may affect the overall response indirectly by altering the levels of endogenous GnRH and, thus complicating the observation.

The anti-proliferative effects of GnRH on NPC cells, although modest, suggested that GnRH was involved, at least in part, in controlling the growth of such cancer cells. Factors, which alter the levels of GnRH, including damage to the hypothalamic-pituitary axis, may have potential effects on the growth of residual NPC cells in the body.

In conclusion, GnRH or its analogues exerted a modest inhibitory effect on cell proliferation and motility in the NPC cells. The presence of GnRH-Rs, in at least a subset of the NPC specimens, suggested that the levels of GnRH may have effects on NPC cells.

\section{Acknowledgements}

The authors would like to thank the Director General of Health Malaysia for permission to publish this study and the Director of the Institute for Medical Research for her support. The authors would also like to thank Dr Katia Manova of the Molecular Cytology Core Facility, Memorial Sloan Kettering Cancer Centre (New York, USA) and Dr Stephen Cody of Monash Micro Imaging, Monash University (Australia) for their advice on imaging experiments, and Professor George Tsao of The Hong Kong University (Hong Kong, China) and staff at the Institute for Medical Research and Monash University Sunway Campus for their support. This study was funded by the Ministry of Health of Malaysia [MRG-IMR-2007-NPC (06-059) and 07-034].

\section{References}

1. Harrison GS, Wierman ME, Nett TM and Glode LM: Gonadotropin-releasing hormone and its receptor in normal and malignant cells. Endocr Relat Cancer 11: 725-748, 2004

2. Rothman MS and Wierman ME: The role of gonadotropin releasing hormone in normal and pathologic endocrine processes Curr Opin Endocrinol Diabetes Obes 14: 306-310, 2007.

3. Everest HM, Hislop JN, Harding T, Uney JB, Flynn A, Millar RP and McArdle CA: Signaling and antiproliferative effects mediated by GnRH receptors after expression in breast cancer cells using recombinant adenovirus. Endocrinology 142: 4663-4672, 2001.

4. Nagy A and Schally AV: Targeting of cytotoxic luteinizing hormone-releasing hormone analogs to breast, ovarian, endometrial and prostate cancers. Biol Reprod 73: 851-859, 2005.

5. Schally AV and Nagy A: Chemotherapy targeted to cancers through tumoral hormone receptors. Trends Endocrinol Metab 15: 300-310, 2004.

6. Labrie F: Hormonal therapy of prostate cancer. Prog Brain Res 182: 321-341, 2010.

7. Park DW, Choi KC, MacCalman CD and Leung PC: Gonadotropin-releasing hormone (GnRH)-I and GnRH-II induce cell growth inhibition in human endometrial cancer cells: Involvement of integrin beta 3 and focal adhesion kinase. Reprod Biol Endocrinol 7: 81, 2009.

8. Grundker $\mathrm{C}$ and Emons G: Role of gonadotropin-releasing hormone $(\mathrm{GnRH})$ in ovarian cancer. Reprod Biol Endocrinol 1: $65,2003$.

9. Szepeshazi K, Schally AV and Halmos G: LH-RH receptors in human colorectal cancers: Unexpected molecular targets for experimental therapy. Int J Oncol 30: 1485-1492, 2007.

10. Moretti RM, Montagnani Marelli M, Mai S and Limonta P: Gonadotropin-releasing hormoneagonists suppress melanomacell motility and invasiveness through the inhibition of alpha3 integrin and MMP-2 expression and activity. Int J Oncol 33: 405-413, 2008.

11. Bahk JY, Kim MO, Park MS, Lee HY, Lee JH, Chung BC and Min SK: Gonadotropin-releasing hormone $(\mathrm{GnRH})$ and $\mathrm{GnRH}$ receptor in bladder cancer epithelia and GnRH effect on bladder cancer cell proliferation. Urol Int 80: 431-438, 2008.

12. Montagnani Marelli M, Moretti RM, Januszkiewicz-Caulier J, Motta M and Limonta P: Gonadotropin-releasing hormone $(\mathrm{GnRH})$ receptors in tumors: a new rationale for the therapeutical application of $\mathrm{GnRH}$ analogs in cancer patients? Curr Cancer Drug Targets 6: 257-269, 2006.

13. Chang ET and Adami HO: The enigmatic epidemiology of nasopharyngeal carcinoma. Cancer Epidemiol Biomarkers Prev 15: 1765-1777, 2006.

14. Pua KC, Khoo AS, Yap YY, Subramaniam SK, Ong CA, Gopala Krishnan G, Shahid H; Malaysian Nasopharyngeal Carcinoma Study Group: Nasopharyngeal carcinoma database. Med J Malaysia 63 (Suppl C): 59-62, 2008.

15. Darzy K: Endocrine complications following radiotherapy and chemotherapy for nasopharyngeal carcinoma. In: Carcinogenesis, Diagnosis, and Molecular Targeted Treatment for Nasopharyngeal Carcinoma. Shih-Shun Chen (Ed.) InTech China, Shanghai, China, pp133-154, 2012. 
16. Huang DP, Ho JH, Poon YF, Chew EC, Saw D, Lui M, Li CL, Mak LS, Lai SH and Lau WH: Establishment of a cell line (NPC/HK1) from a differentiated squamous carcinoma of the nasopharynx. Int J Cancer 26: 127-132, 1980.

17. Cheung ST, Huang DP, Hui AB, Lo KW, Ko CW, Tsang YS, Wong N, Whitney BM and Lee JC: Nasopharyngeal carcinoma cell line (C666-1) consistently harbouring Epstein-Barr virus. Int J Cancer 83: 121-126, 1999.

18. Tsao SW, Wang X, Liu Y, Cheung YC, Feng H, Zheng Z, Wong N, Yuen PW, Lo AK, Wong YC, et al: Establishment of two immortalized nasopharyngeal epithelial cell lines using SV40 large T and HPV16E6/E7 viral oncogenes. Biochim Biophys Acta 1590: $150-158,2002$.

19. Li HM, Man C, Jin Y, Deng W, Yip YL, Feng HC, Cheung YC, Lo KW, Meltzer PS, Wu ZG, et al: Molecular and cytogenetic changes involved in the immortalization of nasopharyngeal epithelial cells by telomerase. Int J Cancer 119: 1567-1576, 2006.

20. Sengupta S, den Boon JA, Chen IH, Newton MA, Dahl DB Chen M, Cheng YJ, Westra WH, Chen CJ, Hildesheim A, et al: Genome-wide expression profiling reveals EBV-associated inhibition of MHC class I expression in nasopharyngeal carcinoma. Cancer Res 66: 7999-8006, 2006.

21. Chan SY, Choy KW, Tsao SW, Tao Q, Tang T, Chung GT and Lo KW: Authentication of nasopharyngeal carcinoma tumor lines. Int J Cancer 122: 2169-2171, 2008.

22. Imai A and Tamaya T: GnRH receptor and apoptotic signaling. Vitam Horm 59: 1-33, 2000.

23. Morgan K, Stewart AJ, Miller N, Mullen P, Muir M, Dodds M, Medda F, Harrison D, Langdon S and Millar RP: Gonadotropin-releasing hormone receptor levels and cell context affect tumor cell responses to agonist in vitro and in vivo. Cancer Res 68: 6331-6340, 2008
24. Goodwin D, Varamini P, Simerska P and Toth I: Stability, permeability and growth-inhibitory properties of gonadotropin-releasing hormone liposaccharides. Pharm Res 32: 1570-1584. 2015.

25. Conn PM, McArdle CA, Andrews WV and Huckle WR: The molecular basis of gonadotropin-releasing hormone $(\mathrm{GnRH})$ action in the pituitary gonadotrope. Biol Reprod 36: 17-35, 1987.

26. Cheung LW and Wong AS: Gonadotropin-releasing hormone: GnRH receptor signaling in extrapituitary tissues. Febs J 275: 5479-5495, 2008.

27. Chen CL, Cheung LW, Lau MT, Choi JH, Auersperg N, Wang HS, Wong AS and Leung PC: Differential role of gonadotropin-releasing hormone on human ovarian epithelial cancer cell invasion. Endocrine 31: 311-320, 2007.

28. Enomoto M, Utsumi M and Park MK: Gonadotropin-releasing hormone induces actin cytoskeleton remodeling and affects cell migration in a cell-type-specific manner in TSU-Pr1 and DU145 cells. Endocrinology 147: 530-542, 2006.

29. Cheung LW, Leung PC and Wong AS: Gonadotropin-releasing hormone promotes ovarian cancer cell invasiveness through c-Jun NH2-terminal kinase-mediated activation of matrix metalloproteinase (MMP)-2 and MMP-9. Cancer Res 66: 10902-10910, 2006.

30. Aguilar-Rojas A and Huerta-Reyes M: Human gonadotropin-releasing hormone receptor-activated cellular functions and signaling pathways in extra-pituitary tissues and cancer cells (Review). Oncol Rep 22: 981-990, 2009.

31. Kakar SS, Malik MT, Winters SJ and Mazhawidza W: Gonadotropin-releasing hormone receptors: Structure, expression and signaling transduction. Vitam Horm 69: 151-207, 2004.

32. Arencibia JM and Schally AV: Luteinizing hormone-releasing hormone as an autocrine growth factor in ES-2 ovarian cancer cell line. Int J Oncol 16: 1009-1013, 2000. 